\title{
Educação ambiental e paradigma da complexidade: aproximações entre ciências naturais e ciências humanas
}

\author{
Adriana Massaê Kataoka ${ }^{1}$ e Maria Manuela Morais ${ }^{2}$ \\ 1 Doutora em Ecologia e Recursos Naturais pela Universidade Federal de São Carlos, Brasil. Professora adjunta da Universidade \\ Estadual do Centro-Oeste do Estado do Paraná - Brasil. \\ 2 Doutora em Biologia pela Universidade de Évora-Portugal. Professora Auxiliar da Universidade de Évora - Portugal
}

RESUMO: Nos últimos anos a educação ambiental (EA) tem se firmado como um campo do conhecimento e de pesquisa que agrega contribuições de diferentes epistemologias. O conceito de EA surge por volta da década de setenta, inserido num contexto de lutas sociais ou direitos fundamentais. Posteriormente assume um caráter ambiental, marcado por uma visão naturalista, adotando concepções da biologia, numa atitude ecocêntrica, preocupada com a conservação dos ecossistemas e da biodiversidade, afastando-se do contexto social. Após 2004 começam a surgir as primeiras críticas a esta abordagem conceitual, e a EA passa a ser reconhecida como "Educação", integrando a dimensão humana, em seus aspectos sociais, políticos e econômicos. Consideramos que nesta caminhada a EA ampliou a capacidade de compreensão das múltiplas interações entre sociedade e ambiente, se posicionando de forma privilegiada para enfrentamento da crise socioambiental, na busca da transformação da relação sociedade e natureza. Todavia, como um pêndulo, a EA saiu de um extremo, ou seja, das abordagens que privilegiam o olhar das ciências naturais para o das ciências humanas, frequentemente carentes de informações específicas que permitam a compreensão dos fenômenos naturais. Considerando todo este percurso, propomos fazer uma reflexão inspirada em Morin que defende a humanização das ciências naturais e a naturalização das ciências sociais. Essa perspectiva epistemológica pode contribuir para a inserção transversal da EA no âmbito do ensino formal, quiçá do ensino superior, contribuindo na construção do conhecimento transdisciplinar envolvendo o indivíduo, a sociedade e a natureza, como um só elemento de reflexão.

Palavras-chave: Ambiente. Educação. Sociedade. Complexidade

\section{Environmental education and complexity paradigm: Approaches between natural sciences and the humanities}

ABSTRACT: In recent years environmental education (EA) has been established as a field of knowledge and research that adds contributions from different epistemologies. The EA concept emerged in the 1970s, in the context of social struggles or fundamental rights. Subsequently it assumes an environmental character, marked by a naturalistic vision, adopting conceptions of biology, in an ecocentric attitude, concerned with the conservation of ecosystems and biodiversity, moving away from the social context. After 2004, the first criticisms of this conceptual approach begin to emerge, and EA is now recognized as "Education", integrating the human dimension in its social, political and economic aspects. We consider that in this walk EA extended the capacity to un- 
derstand the multiple interactions between society and the environment, positioning itself in a privileged way to face the socio-environmental crisis, in the search for the transformation of the relation society and nature. However, as a pendulum, EA has come out of an extreme, that is, approaches that favor the look of the natural sciences to that of the human sciences, often lacking specific information that allow the understanding of natural phenomena. Considering all this course, we propose to make a reflection inspired by Morin that defends the humanization of the natural sciences and the naturalization of the social sciences. This epistemological perspective can contribute to the transversal insertion of the $A E$ in the scope of the formal education, perhaps of the higher education, contributing in the construction of the transdisciplinary knowledge involving the individual, the society and the nature, as a single element of reflection.

Keywords: Environment. Education. Society. Complexity

\section{INTRODUÇÃO}

As ciências humanas não têm consciência dos caracteres físicos e biológicos dos fenômenos humanos. As ciências naturais não têm consciência da sua inscrição numa cultura, numa sociedade, numa história. As ciências não têm consciência do seu papel na sociedade. As ciências não têm consciência dos princípios ocultos que comandam as suas elucidações. As ciências não têm consciência de que lhes falta uma consciência (Morin, 2014).

Sabemos que já existe um reconhecimento da Educação Ambiental (EA) enquanto campo do conhecimento e que, desde o seu surgimento, tem atuado em um campo de disputas entre tendências pedagógicas e epistemológicas. Talvez por se tratar de um campo de convergência entre abordagens tão distintas como das ciências naturais e das ciências humanas, essas disputas ainda se fazem presentes, o que leva muitos pesquisadores a sinalizarem para a necessidade de uma identidade frente a outros campos da educação.

A centralidade da educação, no que se refere à EA, foi conquistada ao longo de sua trajetória à medida que se aprofundavam as reflexões e ampliava-se a clareza de seu papel, enquanto proposta educativa. Nessa trajetória, na qual se afirmava seu papel educativo, inúmeras pesquisas contribuíram ao apontar para a insuficiência de uma concepção de ambiente como natureza e para as limitações de uma abordagem empírico-analítica quando se trata da pesquisa em EA. Assim, os aspectos naturais começaram a perder espaço e, mais do que isso, quando mencionados, em sua maioria, passou-se a the conferir uma conotação quase pejorativa. Na mesma medida, os biólogos e a natureza se afastavam do diálogo com a EA.

Sendo assim, a proposta deste ensaio é realizar uma reflexão sobre possíveis contribuições da teoria da complexidade e sobre a necessidade da aproximação entre as ciências naturais e ciências humanas no campo da EA, visto que a EA é um campo do conhecimento polissêmico e em construção. Essa proposta se justifica em função de a EA envolver duas grandes áreas das ciências, sendo as humanas e naturais e por identificarmos o deslocamento de suas contribuições ao longo de sua trajetória, em seu início mais fortemente a- 
trelado as ciências naturais para, na atualidade, se articular com as ciências humanas.

Para tanto, consideramos pertinente fazer algumas considerações acerca da proposta. A primeira delas é que reconhecemos a EA como parte da grande área do conhecimento das ciências humanas e, portanto, uma abordagem empírico-analítica seria um retrocesso. Reconhecemos que a concepção de meio socioambiental é superior quando comparada à concepção fragmentada de ambiente, a qual apenas considera a dimensão natural. Também entendemos que a criticidade é elemento fundamental da EA, assim como as contribuições de outras abordagens. Desta forma, nossa proposta não pretende negar avanços já conquistados no campo da EA, que em muito contribuíram com a sua qualificação, mas propomos trazer a dimensão natural para o diálogo com os avanços já consolidados nesse campo do conhecimento.

Não temos a pretensão, neste ensaio, de apresentar uma receita de como deve se dar a aproximação entre as ciências naturais e humanas. Restringimo-nos a sinalizar para algumas possibilidades dessa aproximação. Para tanto, organizamos a nossa reflexão em três momentos: no primeiro, contextualizamos o surgimento da EA em um cenário de extrema complexidade socioambiental; no segundo, trazemos alguns princípios da teoria da complexidadede Edgar Morin e algumas aproximações já realizadas por alguns autores da EA entre a teoria da complexidade e o campo da EA e, finalmente, discorremos sobre algumas possibilidades de aproximação entre as ciências naturais e humanas a partir de Morin.

\section{A COMPLEXA TRAMA SOCIOAMBIENTAL EM QUE SE INSERE A EA}

Compreender o passado, analisar o presente e ter a capacidade de perspetivar o futuro exige um posicionamento filosófico fundamental para que o ser humano se questione sobre quem é, onde se insere no Planeta Terra, para onde a sociedade por ele criada se dirige e porquê. Esta postura requer uma abertura à inter e transdisciplinaridade que integre os diferentes fatores relacionados com as alterações globais, também elas interrelacionadas. Combinando, por exemplo, os efeitos das alterações climáticas com o crescimento populacional, com o desenvolvimento social e econômico e com a globalização e urbanização, percebemos como a economia vigente tem contribuído para uma alteração da paisagem natural em simultâneo com uma "invenção" de múltiplos bens e serviços com origem nos recursos naturais.

No século XX, influenciada pelos horrores de duas guerras mundiais, pelas ameaças nucleares e ambientais globais, surge uma nova perspetiva de interpretação dos processos históricos. De facto, a seguir da II Guerra Mundial, assistiu-se a um crescimento da ciência e tecnologia e a um aumento da produção de bens e serviços. Em consequência, dá-se uma explosão de empreendimentos que, para além de causar enormes injustiças sociais, promovem efeitos desastrosas no planeta Terra. Estes eventos de efeitos imediatamente impercetíveis foram descritos por Steffen et al (2007) como a "Grande Aceleração". Ainda conforme Braga et al (2014): 
Em 50 anos a população mundial duplicou para valores aproximadamente a 6 biliões (final do século XX); a economia global aumentou mais de 15 vezes. Desde 1960 que o consumo do petróleo tem crescido a uma taxa de 3,5. O número de automóveis aumentou drasticamente de cerca de $40 \mathrm{mi}$ Ihões no final da II Grande Guerra para 700 milhões. De 1950 a 2000, a percentagem de população humana a viver em áreas urbanas cresceu de $30 \%$ para $50 \%$, assistindo-se a um aumento constante. Os países ricos com $20 \%$ da população planetária consomem $80 \%$ dos recursos naturais" (p. 3).

Segundo Crutzen e Stoermer (2000) como consequência global, o ser humano tem alterado os ecossistemas naturais mais rapidamente do que em qualquer outro período da história da humanidade. A comunidade científica internacional refere termos entrado numa nova época geológica - Antropocene, que sucede ao Holocene - época correspondente a 11.700 anos geológicos, onde o clima permaneceu marcadamente estável. Nos dois últimos séculos, os efeitos do ser humano no ambiente foi vertiginoso, assistimos a: i) uma enorme perca de biodiversidade à escala planetária; ii) a concentração atmosférica de diferentes gases de efeito estufa tem aumentado substancialmente. Devido às emissões antropogénicas de $\mathrm{CO}_{2}$, o clima global sedesviou significativamente do comportamento natural, para muitos milênios à frente. A terra está a aquecer rapidamente segundo o IPCC (2007); iii) presentemente, a maior percentagem de conversão de azoto atmosférico em formas reativas resulta da produção de fertilizantes e da combustão de combustíveis fósseis. No seu conjunto superior à totalidade dos efeitos de todos os outros processos naturais.

Estes efeitos globais tão bem descritos por Steffen et al (2007) como a "Grande Aceleração" acontecem no âmbito de um contexto intelectual, cultural, político e legal, onde não foram devidamente analisados os impactos reais no sistema Terra. De acordo com Silva Maia (2015), a crise ambiental tem as suas raízes no modelo de produção que considera a natureza como recurso e a valoriza como mercadoria ao serviço de uma lógica capitalista.

De fato, nos anos 60 (anos de ouro do desenvolvimento ocidental), desenvolveu-se a ideia de que a ciência poderia salvar os problemas do mundo. Nos anos 70, apareceram os primeiros sinais contraditórios (crise do petróleo de 1973 e a evidência da poluição e degradação dos ecossistemas naturais). O final da guerra fria, no início dos anos 90, trouxe alguma esperança a nível do entendimento global. No entanto, a escalada dos preços do petróleo aumentou a consciência de que a era do petróleo barato poderia estar a terminar (BRAGAet al, 2014).

No final dos anos 80 e início dos anos 90, emerge uma filosofia intercultural crítica como resposta aos desafios provocados pela globalização neoliberal, quer ao nível econômico, quer ao nível político, bem como pela sua tendência de "estandardização" cultural e ainda pelos crescentes conflitos sociais, culturais e ambientais. Desponta uma necessidade da troca intercultural, uma troca de saberes, com o pressuposto filosófico de que cada forma de pensamento e cada filosofia é determinada por uma contextualidade e uma interdependência cultural. As principais preocupações são a superação do eurocentrismo, a aceitação de outras culturas/outros saberes ao mesmo nível hierárquico e a promoção do diálogo entre as culturas/entre povos/entre saberes. Nesta concepção, a educação é entendida como um processo dialógico de formação de sujeitos sociais emancipados, autores da 
sua própria história em nome de uma ética da vida (FREIRE, 1987; 1992), e de uma educação inserida na vida e nas preocupações atuais.

É neste contexto de crise civilizatória, que envolve uma complexa trama de ações e retroações entre a dimensão natural e a dimensão humana, que em meados da década de 80 e início dos anos 90, surge a EA no Brasil,favorecida pelos movimentos sociais emancipatórios de rutura com a modernidade capitalista (LOUREIRO, 2012), os quais promovem a consciencialização de realidades sociais e direito de exercer cidadania.

Nesta nova exigência de escolha ético-política, a EA se dá na relação entre o "eu" e o "outro", pela prática social reflexiva e fundamentada teoricamente (LOUREIRO, 2012). A "ação consciencializadora é mútua, envolve capacidade crítica, diálogo, a assimilação de diferentes saberes e a transformação ativa da realidade e das condições de vida" (Ibid, 2012, p. 34). De acordo com Carvalho (2004), a EA,em sua vertente crítica, acrescenta a especificidade de:

compreender as relações sociedade-natureza e intervir sobre os problemas e conflitos ambientais....e contribuir para uma mudança de valores e atitudes, contribuindo para a formação de um sujeito ecológico, um tipo de subjetividade orientadas por sensibilidades solidárias com o meio social e ambiental, modelo para a formação de indivíduos e grupos sociais capazes de identificar, problematizar e agir em relação às questões socioambientais (p.18) [grifo da autora].

Neste sentido, a EA pode ser entendida como um processo de resgate de valores esquecidos na relação histórica dos seres humanos com o ambiente (MAIA, 2015), fortalecendose através de ações que potenciam a integração do indivíduo com o que o rodeia em superação da dicotomia sociedade-natureza. Este posicionamento,sobretudo na ética da Pedagogia Histórico-Crítica (Ibid, 2015), pressupõe um profundo debate político assente em normas de superação de dominantes capitalistas que rompa com um discurso essencialmente centrado na perspetiva ecológica e naturalista que contribui para o "capitalismo verde", assente em mudanças superficiais e não de lógica societária. Na mesma linha de pensamento, Guimarães (2004) se distancia de uma pedagogia, que refere ser conservadora, de carácter naturalista, fragmentada e incapaz de contribuir para a transformação de uma realidade que historicamente nos tem conduzido a uma grave crise socioambiental.

Ainda segundo Guimarães (2004), esta concepção não supera o cientificismo cartesiano e o antropocentrismo, historicamente presente de forma hegemônica na sociedade moderna. Foca-se na parte, vê o mundo fragmentado, estabelece uma hierarquia que constrói a lógica da dominância, na qual se perdem a riqueza e a diversidade da relação sociedadenatureza. Esta é uma perspetiva simplista e reduzida de perceber uma realidade que é complexa e que não pode ser considerada como a simples soma das partes. Nesta perspetiva, os aspetos naturais e, na mesma medida, os biólogos e a natureza se afastam do diálogo com a dimensão humana.

Por outro lado, a crise econômica e ambiental que se vive presentemente (início em 2008, não se antevendo a sua solução) nos conduz à reflexão sobre a falácia das preocupações ambientais no âmbito do conceito atual sobre desenvolvimento econômico e social sustentável. A prova disso é a enorme dificuldade para definir indicadores que avaliem o 
desenvolvimento sustentável ao nível global. Como refere Leff (2010), "o desenvolvimento sustentável mostra-se pouco duradouro porque não é ecologicamente sustentável!" (p. 57).

A partir do exposto, fica evidente o deslocamente de uma perspectiva naturalista de ambiente para a ampliação das discussões que envolvem a crítica à organização social, pautada em um modelo econômico capitalista neoliberal.Concordamos que a ampliação das discussões ambientais para a esfera humana agregou conteúdo e maior clareza sobre a complexidade da temática, além de sinalizar para novos horizontes de enfrentamento que não apenas uma EA catastrófica, conteudista ou adestradora. Por outro lado, a dimensão natural, ou seja, o olhar das ciências naturais se restringiu até se limitar apenas a sua menção. Não nos esqueçamos de que, na sua fase inicial, a EA foi marcada por uma tradição naturalista (CARVALHO, 2004), à qual foi necessário acrescentar a componente social através de um esforço para superar a dicotomia sociedade/ambiente. Atualmente, num período marcado por uma enorme degradação ambiental, o esforço é o de colocar ambos os componentes ligados ao mesmo nível de importância numa área de convergência de novos horizontes de compreensão (STEIL e CARVALHO, 2014). Esta área não é mais que o sistema Terra, onde o humano se funde na Natureza na essência da sua condição de espécie biológica que integra os ciclos dos elementos (nitrogênio, fósforo e matéria orgânica).

Acreditamos que, em face à grande complexidadeda da crise socioambiental, o conhecimento científico das ciências naturais não pode se limitar a uma breve menção. Os conhecimentos sobre os problemas ambientais físicos e biológicos de ordem global e as suas ameaças à bioesfera como um todo, ou ainda os conhecimentos sobre a estrutura e o funcionamento dos ecossistemas e sua biodiversidade, além de contribuirem para medidas que promovam uma utilização racional dos recursos (componente social) sem que se ultrapassem os limites da resiliência em toda a complexidade dos sistemas naturais (componente ambiental), devem de alguma forma estar mais presentes numa EA plural que integre o ser humano à natureza.

É neste sentido que o pensamento complexo de Edgar Morin, pautado em relações dialógicas, aparentemente contraditórias, tais como a parte e o todo, a ordem e a desordem, o simples e o complexo, são um caminho de reflexão para uma compreensão do real global, com toda a sua diversidade física e biológica, numa busca de sentido de vida do ser humano em sintonia com a ordem da natureza. Segundo Boaventura de Sousa Santos (2010), na atual transição paradigmática, para as teorias críticas, a ciência moderna é indispensável, porém insuficiente para compreender o mundo. Ela precisa se articular com outras culturas e filosofias.

Em relação ao impassse apresentado por Santos (2010), a teoria da complexidade de Edgar Morin pode contribuir com essa reflexão.Essa teoria ou também chamado Paradigma da Complexidade propõe uma nova forma de compreender os fenômenos da sociedade , do ser humano ou a própra ciência a partir de contribuições de diferentes áreas do conhecimento,como veremos a seguir. 


\section{TEORIA DA COMPLEXIDADE: PRINCIPAIS IDEIAS E SUA RELAÇÃO COM A EA}

Antes de iniciarmos a discussão sobre o que é o pensamento complexo e a sua importância, consideramos fundamental explicar que a sua necessidade se impõem à medida que emerge a insuficiência do pensamento simplificador ou cartesiano. Esse pensamento é a própria ciência moderna, ou seja, o pensamento científico e sobre ele, Morin (2014) explica que:

essa ciência elucidativa, enriquecedora, conquistadora e triunfante, apresenta-nos, cada vez mais, problemas graves que se referem ao conhecimento que produz, à ação que determina, à sociedade que transforma. Essa ciência libertadora traz, ao mesmo tempo, possibilidades terríveis de subjugação. Esse conhecimento vivo é o mesmo que produziu a ameaça do aniquilamento da humanidade (p.16).

Quando Morin trata das limitações apontadas pela ciência moderna, em muito ele associa a crítica à fragmentação do conhecimento, que é compartilhada pelos educadores ambientais. No campo da EA, a crítica à fragmentação se estende à concepção de ambiente, entendido como um conceito que envolve múltiplas dimensões, seja física, biológica, social, política e econômica. Entendemos, portanto, que uma visão disjuntiva de ambiente ou especializada não dá conta de compreender a intricada rede de relações que são envolvidas quando se trata da temática ambiental.

Loureiro (2012), respeitado educador ambiental da abordagem crítica da EA, reconhece Edgar Morin como um dos autores mais recorrentes como referência pelos educadores ambientais, muito embora faça uma ressalva em relação à ausência ou secundarização em suas publicações de processos históricos e políticos na análise da transformação societária e nos processos educativos. Mesmo assim, destaca seu inegável mérito ao trazer a dialética para uma formulação teórica complexa articulada com a tradição crítica no campo ecológico.Desta forma, consideramos que a teoria da complexidade oferece importantes elementos a serem incorporados pela EA. Em contraposição ao paradigma simplificador, Morin (2015a) propõe que:

A um primeiro olhar, a complexidade é um tecido (complexus:o que é tecido junto) de constituintes heterogêneas inseparavelmente associadas: ela coloca o paradoxo do uno e do múltiplo. Num segundo momento, a complexidade é efetivamente o tecido de acontecimentos, ações e interações, retroações, determinações, acaso que constituem nosso mundo fenomênico (p.13).

Para pensar a complexidade, Morin (2015a) apresenta três princípios, o princípio dialógico, o princípio da recursão organizacional e o princípio hologramático. O princípio dialógico se refere à possibilidade do que é antagônico também ser complementar. Ele defende que esse princípio permite manter a dualidade no seio da unidade e associar, ao mesmo tempo, dois termos complementares e antagônicos.

Sobre o princípio da recursão organizacional, Morin (2015a) explica que se trata de um processo em que os produtos e os efeitos são, ao mesmo tempo, causa e produtores do que os produz. Esse princípio, a nosso ver, oferece importantes elementos a serem aplica- 
dos na EA, quando se trata da polarização feita por algumas abordagens da EA relacionadas ao indivíduo e à sociedade que, dependendo da abordagem, uma é evidenciada em detrimento da outra. Para Morin (2015a, p.74), "a sociedade é produzida pelas interações entre indivíduos, mas a sociedade uma vez produzida, retroage sobre os indivíduos e os produz". E ele complementa que "[...] os indivíduos produzem a sociedade que produz os indivíduos, somos ao mesmo tempo produtores e produtos".

O terceiro princípio, que é o hologramático, segundo Morin (2015a), pode ser encontrado no mundo biológico e no mundo sociológico. Esse princípio explica que o todo está nas partes e as partes estão no todo. $O$ autor exemplifica essa ideia por meio da relação antropossocial que, desde a infância, a sociedade é introduzida nas pessoas através das primeiras apreensões e imposições familiares, ao mesmo tempo que as pessoas fazem parte da sociedade.

A partir dessa formulação, Morin (2015a) desenvolve e aprofunda diferentes aspectos relacionados a esse paradigma e suas implicações para os mais diversos setores da vida e da sociedade. $\mathrm{O}$ autor destaca que enquanto o pensamento simplificador desintegra, o pensamento complexo não nega o pensamento simplificador, mas o integra, busca a articulação entre os campos disciplinares e, desta forma, busca o pensamento multidimensional.

Articulado mais diretamente com o campo educacional, Morin (2000) escreveu a obra "Os Setes Saberes Necessários à Educação do Futuro", em atendimento a uma solicitação da UNESCO, com o objetivo de aprofundar a visão transdisciplinar da educação. Nesta obra, os princípios da teoria da complexidade podem ser encontrados implicitamente nos sete saberes organizados pelo autor, sendo eles: as cegueiras do conhecimento: o erro e a ilusão, os princípios do conhecimento pertinente; ensinar a condição humana, ensinar a identidade terrena, enfrentar as incertezas, ensinar a compreensão e a ética do gênero humano. $O$ texto "pretende, única e essencialmente, expor problemas centrais ou fundamentais que permanecem totalmente ignorados ou esquecidos e que são necessários para se ensinar no próximo século" (MORIN, 2000, p. 13).

Em continuidade as suas contribuições para o campo da educação, em sua obra "A Cabeça Bem-Feita", Morin (2015b) reafirma a necessidade de uma reforma do pensamento, já mencionada em produções anteriores e agora alargada para a necessidade de uma reforma no ensino. Ao tratar da reforma do ensino, o autor reforça que entende o sentido mais restrito do ensino, ao mesmo tempo que considera que a educação comporta um excesso e uma carência. Assim, Morin decide transitar entre os dois termos, dedica a obra ao ensino e à educação, ao mesmo tempo que o chama de ensino educativo.

Vale ressaltar que no prefácio da "A Cabeça Bem-Feita", Morin (2015b) se defende de críticas recorrentes as suas ideias que o acusam de considerar e propor o paradigma da complexidade como o "a poção mágica", capaz de solucionar toda a ordem de problemas. Sobre isso, ele afirma que se trata exatamente do oposto, que para ele a complexidade é um desafio que se propõe a vencer. Nesse sentido, concordamos que a sua proposta nos desafia a dar continuidade a suas proposições e dialoga, por exemplo, com a EA para criar novas possibilidades teóricas e práticas em sintonia com os princípios da EA. 
Essas ideias têm encontrado eco em muitos educadores ambientais, que o tomam como referência, fertilizando suas práticas e produções científicas. Verificamos que cada autor enfatiza determinados aspectos de sua vasta e profunda produção como, por exemplo, Saheb (2017) que adota de maneira prioritária "Os Setes Saberes para uma Educação do Futuro". A autora, ao analisar a relação entre as ideias de Morin e as DCNEA, concluiu que essa obra é uma importante contribuição para a efetivação da EA ao conduzir a superação do reducionismo, da fragmentação e da simplificação do conhecimento. Humberto Callon i(2006) traz inúmeras contribuições para os fundamentos da EA com base em Morin. Ele afirma que a EA traz a possibilidade de uma nova organização por meio da desordenação do pensamento simplificador e reducionista, provocando, assim, pensamentos complexos e críticos em contrapartida do paradigma dominante.

Nessa direção, vale ressaltar os trabalhos de Maria Cândida de Moraes (2010), que possui uma vasta produção na educação articulada com as ideias de Morin e compartilha das mesmas preocupações relacionadas com a temática ambiental que os educadores ambientais. Ela se diferencia na ênfase dada as suas argumentações que, mesmo sem se distanciar da criticidade, enfatiza a necessidade da reforma do pensamento nutrida pela necessária abertura do coração.

Assim, vemos que a presença de Morin no campo da EA não ocorre de maneira homogênea. Antonio, Kataoka e Neumann (2017), em uma análise preliminar de dez artigos sobre EA com referência a Morin, investigaram quais elementos da complexidade eram evidenciados nas pesquisas. Os elementos que apareceram forama unificação das ciências, a crítica à fragmentação, a multidimensionalidade do ser, a interdisciplinaridade e as ideias contraditórias e complementares. Os aspectos levantados, porém, ocorreram de forma isolada e sem a devida contextualização, o que se supõe que os autores dessas pesquisas talvez não tinham compreendido plenamente ainda a amplitude da teoria de Morin, mas reconhecem já que a aproximação entre a teoria da complexidade e a EA é importante. Esses dados corroboram Loureiro (2012).

Ainda assim, mesmo reconhecendo Morin como uma das referências teóricas da EA, como já destacado por Loureiro (2012), consideramos que ainda há muito a ser explorado em favor da EA em relação a sua teoria. Acreditamos, inclusive, que as ideias de Morin possuem um potencial para provocar questionamentos sobre abordagens da EA já consolidadas por meio de uma perspectiva ainda pouca explorada.Especialmente no que se refere à importância da integração entre ciências naturais e humanas, de uma maneira mais simétrica e não deslocada, como tem ocorrido na EA.

\section{A Aproximação entre CiênCias naturais e ClênCias Humanas: um diálogo possível A PARTIR DE EDGAR MORIN}

Entre todos os aspectos apontados por Morin (2014), vamos nos deter ao distanciamento das ciências naturais em relação às ciências humanas. Sobre possíveis aproximações entre ambas, em sua obra "Ciência com Consciência", Morin discorre sobre a importância dessa aproximação em contraposição ao paradigma disjuntivo ou fragmentado. Do ponto 
de vista das ciências da natureza, exclui-se o espírito humano e a cultura que produzem essas mesmas ciências, e, por outro lado, as ciências humanas são incapazes de pensar o homem enquanto seres vivos biologicamente constituídos.

Compartilhamos da mesma preocupação de Morin ao observarmos, nas produções da $E A$, uma ênfase direcionada para um sujeito humano, essencialmente preocupado com aspetos sociais, muitas vezes desligado do mundo natural.Nos interessa, especialmente, essa aproximação, uma vez que o campo da EA, devido a sua natureza plural, tem agregado esses dois campos do conhecimento, ora para o campo das ciências naturais ora para o das ciências humanas.

A EA, devido a sua natureza múltipla, tem agregado diferentes epistemologias, em sua maior parte, aquelas já consolidadas na educação. Contudo, alguns pesquisadores têm apontado para a importância de uma possível epistemologia própria, com vistas a uma totalidade mais ampla, mais simétrica. Maia (2017) propõe uma superação de perspectivas disciplinares e até mesmo interdisciplinares pela totalidade. A Ecologia Cosmocena tem sido apontada por Pereira (2016), a partir de um olhar hermenêutico, como uma alternativa para pensarmos as relações entre seres vivos e não vivos, pautada em uma perspectiva ecológica enquanto morada. Pereira (2016) se aproxima de Morin (2000) quando enfatiza a necessidade de um reposicionamento do ser humano no cosmos, quando menciona a condição humana como biológica, psicológica, social, ambiental e espiritual, ao considerar a multidimensionalidade do ser, na verdade ampliando a ideia de Morin sobre o ser.Ao propormos uma aproximação entre ciências naturais e humanas, de certa forma, procuramos resgatar a relação sociedade e natureza no bojo da EA que seja mais simétrica. Pensamos em uma aproximação que integre a dimensão humana à dimensão natural e não se limite a mencionar a dimensão natural de uma maneira esvaziada e vice-versa.

Em sintonia com essa ideia, um caminho que começa a ser delineado e que radicaliza a aproximação entre ciências naturais e humanas se refere à noção de epistemologias ecológicas, cunhadopor investigadores da área da antropologia social (Carlos Aberto Steil) e da educação (Isabel Cristina de Moura Carvalho). Eles defendem que essa perspectiva considera o ambiente como alteridade, independente das representações humanas, "que tem deixado ecoar a voz das coisas e o fluxo dos materiais, evitando recair nos determinismos, sejam eles culturais ou biológicos" (STEIL e CARVALHO, 2014, p.183). Este conceito posiciona o ser humano numa rede de relações simétricas com os outras espécies e com a natureza, reciprocamente determinadas, sem hierarquia.

Consequentemente, opõe-se a uma ontologia antropocêntrica e propõe a superação do etnocentrismo. Vai para além do reconhecimento da diversidade cultural e o "outro", nesta nova concepção, estende-se aos organismos não humanos que habitam o mundo (STEIL e CARVALHO, 2014). Ao desfazer a linha que separa natureza e cultura, esta concepção reconhece que os não humanos estão também abertos ao mundo. Negam a hierarquia estabelecida por Heidegger entre noção de pedra sem mundo, animal pobre de mundo e o ser humano, no topo da pirâmide, formulador de mundo (STEIL e CARVALHO, 2014; CARVALHO, 2014). "Se a pedra possui um mundo, torna-se possível pensar em uma perspetiva da pedra" (STEIL e CARVALHO, 2014, p.167). De uma forma que resgata a relação transver- 
sal entre ser humano e natureza, os "Novos Materialismos e as Epistemologias Ecológicas" (CARVALHO, 2014) questionam sobre o lugar que os seres humanos ocupam no mundo de outros organismos não humanos e que compartilham o mesmo ambiente. Questionam o posicionamento do ser humano no sistema Terra interligado com as outras espécies e globalmente condicionados pelos elementos físicos responsáveis pela criação de um ambiente propício ao desenvolvimento da biodiversidade global, característica do nosso Planeta. "Trata-se de perceber o pulsar do mundo onde vivemos e com o qual interagimos constantemente, ainda que essa vida seja constantemente apagada e silenciada em nossa cultura humanocentrada" (CARVALHO, 2014, p.73).

Um dos aspetos que mais nos interessa nesta nova concepção, fundamental para uma EA que aproxime as ciências da natureza e as ciências humanas, é a possibilidade da criação de um espaço de debate aberto à interdisciplinaridade nas suas dimensões acadêmicas e pluricultural que consiga romper com as dualidades modernas (tais como natureza e cultura, sujeito e sociedade, corpo e mente, artifício e natureza, sujeito e objeto) (Ibid, 2014) e com a fragmentação da educação vigente tão bem documentada por Morin.

Numa atitude de recusa o etnocentrismo, fascina-nos a possibilidade de aproximação entre grupos humanos detentores de diferentes saberes e práticas ambientais de atuação. Acreditamos que, desta forma, é possível contribuir para uma interação com a natureza numa paisagem redefinida que privilegie relações conscientes com todos os seres que partilham o mesmo território. Todavia, para isso, é necessário pensar e conhecer os processos da natureza através de uma aproximação entre ciências humanas e naturais que, no fundo, contrarie a epistemologia moderna que coloca tensão entre natureza e cultura.

De fato, sabemos que as ciências modernas, sob a exigência da especialização, têm dificultado o diálogo entre as ciências da natureza e humanas, o que tem contribuído para uma postura reducionista fragmentada que, independentemente do objeto real, surge apoiada ou engajada na cultura ou em explicações de caráter mais biológico de índole ambiental, consoante à formação do especialista. Pensamos que é através deste conhecimento plural integrador, que valoriza uma aproximação à natureza e deixa aparecer as ligações que sempre existiram entre humanos e não humanos, que se criam práticas ambientais cotidianas de preservação, adquiridas através de predisposições que se colocam como atitudes diferenciadoras.

Como refere Steil e Carvalho (2014), o "nosso modo de habitar o planeta não está separado do nosso modo de conhecê-lo" (p.163). As epistemologias ecológicas propõem, assim, um modo de operar em termos de conhecimento que não só permite ver o mundo da forma como é imaginado por outras culturas como também abre espaço para o imaginário de outras espécies e elementos que partilham conosco o mesmo universo através de "uma fusão de histórias - da história humana e natural - e que faz de nós todos, convivas e "cocidadãos" de um mesmo mundo global e híbrido" (STEIL e CARVALHO, 2014, p.176). Neste contexto, abre-se dimensão para a aproximação necessária entre ciências naturais e humanas, essencial para uma mudança de paradigma num universo globalmente complexo.

As iniciativas para a aproximação entre ciêncas naturais e humanas ainda são incipentes, mas podem encontrar aderência no paradigma da complexidade proposto por Morin 
(2014), o qual deixa claro que toda teoria dotada de alguma complexidade só pode conservar sua complexidade à custa da recriação intelectual permanente. Entendemos que, desta forma, ele deixa espaço para novas possibilidades, possibilidades essas de recriação que poderão ser aplicadas ao campo da EA como as iniciativas acima citadas. Defendemos que um encontro renovado entre as ciências naturais e humanas poderia se configurar num locus teórico em que teorias das ciências naturais e humanas se encontrem de fato e se misturem de forma produtiva. Acreditamos que novas possibilidades podem emergir desse contato, como possibilidades éticas, políticas e sociais com importantes implicações para o campo da EA com reflexos em seus fundamentos e práticas.

\section{CONSIDERAÇÕES FINAIS}

A EA, enquanto campo do conhecimento polissêmico e que, portanto, agrega contribuições de diferentes áreas como das ciências naturais e ciências humanas, tem propiciado produtivos debates e até disputas de ordem pedagógica e epistemológica.É nesse cenário que este ensaio se propôs a analisar as possíveis contribuições da teoria de complexidade de Morin para a EA e, mais especificamente, a possibilidade da aproximação das ciências naturais e humanas, a partir desse paradigma.

A densa e profunda teoria elaborada por Edgar Morin, apesar de ser adotada como referência no campo da EA por muitos pesquisadores, ainda é explorada em sua superficialidade e agregada a outras tendências já consolidadas pela educação e a EA, como as abordagens crítica, fenomenológica e hermenêutica, de maneira secundarizada. Sinalizamos para um potencial de se constituir em uma abordagem da EA, pela sua abrangência e princípios que permitem, inclusive, integrar as abordagens já existentes, tendo a criticidade como elemento fundamental.

Sobre as possibilidades para a aproximação entre as ciências naturais e humanas, Morin oferece ampla gama de argumentos para essa conciliação e uma teoria consistente e inovadora com um grande potencial para contribuir com o campo da EA. Identificamos nas epistemologias ambientais e novos materialismos uma sintonia com a teoria da complexidade que aponta para uma simetria entre os seres humanos com outras espécies e com a natureza. Acreditamos que essas novas ideias radicalizam o deslocamento da ênfase dada pela EA em relação às ciências humanas e ciências naturais, segundo os autores dessa nova proposta, ambas antropocêntricas. Nosso ensaio sinaliza para novos horizontes para o campo da EA e que poderão trazer profundas implicações para seus fundamentos e suas práticas. Reconhecemos também que nossa reflexão ainda é preliminar e que se faz necessário outras pesquisas para aprofundamento.

\section{REFERÊNCIAS}

ANTONIO, J. M.; KATAOKA, A. M.; NEUMANN, P. A complexidade em Edgar Morin e educação ambiental: da aproximação à integração. XVI Encontro Paranaense de Educação Ambiental, Editora: Setor de Educação da UFPR, Curitiba, 2017. 
BRAGA B.; CHARTRES C.; COSGREVE W. J.; VEIGA DA CUNHA, L.; GLEICK P.H.; KABAT, P.; KADI, M. A.; LOUCKS, P.; LUNDQVIST J.; NARAIN, S.; XIA, J.; Waterandthe Future ofHumanity. Revisting Water Security. Gulbenkian Think Tank on Water and the Future of Humanity, CalousteGulbenkian Foundation. Springer New York Heidelberg Dordrecht London, 2014, p.241.

CALLONI, H.; MARQUES, M. C. A Teoria da Complexidade no Movimento da Educação Ambiental. Revista Didática Sistêmica (Online), Rio Grande-RS, v. 4, p. 1-12, 2006.

CARVALHO, I. C. M. Educação ambiental crítica: nomes e endereçamentos da educação. In: LAYRARGUES, Philippe Pomier (Org.). Identidades da educação ambiental brasileira. Brasília: Ministério do Meio Ambiente, 2004.

CRUTZEN, P. J.; STOERMER, E. F. The "Antropocene". Global Change Newsletter, v.41, p. 17-18, 2000.

FREIRE, P. Pedagogia da Esperança. Rio de Janeiro: Paz e Terra, 1992.

FREIRE, P. Pedagogia do Oprimido. 18.ed. Rio de Janeiro: Paz e Terra, 1987.

GUIMARÃES, M. A. Educação ambiental crítica. In: BRASIL. Ministério do Meio Ambiente. Identidades da educação ambiental brasileira. Brasília, 2004. p.25-34.

IPPC (Intergovernemental Panel on Climate Change) 2007. Contribution of Working Group I to the Fourth Assessment Report of the Intergovernmental Panel on Climate Change, Cambridge University Press, Cambridge, UK, 2007.

LEFF, E. Discursos Sustentáveis. São Paulo: Cortez, 2010.

LOUREIRO. C. F. B. Trajetória e Fundamentos da Educação Ambiental. 4.ed, São Paulo: Cortez, 2012.

MAIA, J. S. da S. Trabalho pedagógico e formação continuada de professores em educação ambiental crítica na escola pública. Ambiência, v 13, edição especial, p.176-174, 2017.

MAIA, J. S. da S. Educação Ambiental Crítica e Formação de Professores. 1. Ed. Curitiba, Appris, 241 p, 2015.

MORIN, E. A cabeça bem feita. 22 ed. Rio de Janeiro: Bertrand Brasil, 2015b.

MORIN, E. Ciência com consciência. 16 ed. Rio de Janeiro: Bertrand Brasil, 2014.

MORIN, E. Introdução ao pensamento complexo. 5.ed. Porto Alegre: Sulina, 2015a.

MORIN, E. Os Sete Saberes necessário à Educação do Futuro. São Paulo: Cortez, 2000.

PEREIRA, V. A. Ecologia Cosmocena: a redefinição do espaço humano no cosmos. 1 ed. Juiz de Fora, MG: GARCIA edizioni, 2016.

SAHEB, D.; RODRIGUES, D.G. A contribuição da Complexidade para as pesquisas em Educação Ambiental. Revista Eletrônica do Mestrado em Educação Ambiental, v. Especial, p. 191-207, 2017.

SANTOS, B. de S. Um discurso sobre as ciências. 16. ed. Porto: B. Sousa Santos e Edições Afrontamento, 2010. 59p.

STEFFEN, W.; CRUTZEN, P.J.; MCNEILL, J.R. The Anthropocene: Are humans now overwhelming the great forces of nature? Ambio, v. 36, n.8, p. 614-621, 2007.

STEIL, C.A; CARVALHO, I.C.M. Epistemologias ecológicas: delimitando um conceito. Mana, v. 20, n.1, p. 163-183, 2014. 